$\sqrt{B}$

J. bio-sci. 17: 89-94, 2009.

ISSN 1023-8654

http://www.banglajol.info/index.php/JBS/index

\title{
ANTIBACTERIAL ACTIVITY AND CYTOTOXICITY OF THREE LECTINS PURIFIED FROM DRUMSTICK (MORINGA OLEFERA LAM.) LEAVES
}

\author{
Shahanaz Khatun, M M H Khan*, M Ashraduzzaman¹, Farzana Pervin, Luthfunnessa Bari 2, N Absar \\ Department of Biochemistry and Molecular Biology, University of Rajshahi, Rajshahi-6205 \\ ${ }^{1}$ Department of Chemistry, Rajshahi University of Engineering and Technology, Rajshahi-6204 \\ ${ }^{2}$ Department of Food Technology and Nutritional Science, Mawlana Bhashani Science and Technology University, \\ Tangail 1902, Bangladesh
}

\begin{abstract}
Context: Plant materials contain glycoproteins (phytolectins) that are toxic in nature may play a key role in the control of various normal and pathological processes in living organisms and have diverse biochemical and diagnostic applications.

Objectives: Screening of three lectins SLL-1, SLL-2 and SLL-3 purified from Drumstick (Moringa oleifera Lam.) leaves for their antibacterial activities and brine shrimp lethality bioassay.

Materials and Methods: Three bioactive lectins were purified from Drumstick leaves by conventional chromatographic methods. The lectins were tested for their antibacterial activities against three pathogenic bacteria- Escherichia coli (gram-negative) Shigella dysenteriae (gram-negative) and Staphylococcus aureus (gram-positive) using the standard disc-diffusion method. Mortality of the brine shrimp naupli was assessed by hality bioassay.

Results: All the lectins showed antibacterial activity against E. coli, Sh. dysenteriae and St. aureus. They also showed cytotoxic effect in brine shrimp (Artemia salina L.) lethality bioassay. The LC 50 values of SLL-1, SLL-2 and SLL-3 were found to be 15.8, 17.78 and $14.12 \mu \mathrm{g} / \mathrm{ml}$ respectively. The experimental results revealed that SLL-3 is more cytotoxic than other lectins. The lectin SLL-3 showed lowest activity whereas SLL-1 showed highest activity against the three bacteria.
\end{abstract}

Conclusion: Results suggest that the extracts from $M$. oleifera leaf can be a source of natural antimicrobials with potential applications in pharmaceutical industry to control coliform bacteria.

Key words: Drumstick, Moringa oleifera, lectins, antibacterial activity, brine shrimp, bioassay

\section{Introduction}

Lectins, are a group of glycoprotein's that binds sugar specifically and reversibly and possesses the unique ability to agglutinate erythrocytes and other types of cells (Boyd 1970). They are widely available in nature as they are found in animals, insects, plants and microorganisms (Lin et al.1981, Linear et al. 1986, Lis and Sharon1986, Sharon and Lis 1989). Lectins are widely distributed in the plant kingdom and are also referred to as phytohemagglutinin. The term phytolectin has been proposed in order to distinguish those lectins which are found in plants from those which are of animal or microbial origin. Both oncogenic and nononcogenic viral transformed cell possess increased susceptibility to agglutination by lectin that exhibit toxic substances even in very small amount to higher animal. Abrin and ricin possess such kinds of characteristics. They inhibit protein synthesis as well as DNA and also RNA in the cell culture.

*Corresponding author: muktabio@yahoo.com 
Moringa oleifera Lam. (Moringaceae) is a plant of subtropical West Indies, Indian origin, widely distributed in the Indo-Bangla subcontinent and cultivated throughout the tropical belt (Sastri 1962, Nadkarni 1976). A small genus of quick growing trees is distributed in Bangladesh, India, Arabia, Asia Minor, Africa, Egypt and Australia. It is widely cultivated in tropics for its edible fruits. The leaves contain vitamin A, vitamin $C$ and are considered to be useful in scurvy and hay fever. In developing tropical countries, $M$. oleifera have been used to combat malnutrition, especially among infants and nursing mothers (Fuglie 1999). Its bark is regarded as an antiscorbic and it exudes a reddish gum sometimes used for diarrhea. The roots of $M$. oleifera are bitter, act as a tonic to the body and lungs, and an expectorant. The leaf tea is used to treat gastric ulcers and diarrhea while flower juice improves the quality and flow of mothers' milk when breast feeding and is also useful for urinary problems as it encourages urination. The pharmacological and biological activities of $M$. oleifera have been studied. Aqueous extract of $M$. oleifera has been found to have anti-nociceptive and antiinflammatory activities (Sulaiman et al. 2008). Mahajan et al. (2007) reported that the seed extract of $M$. oleifera had an effect on toluene diisocyanate-induced immune-mediated inflammatory responses in rats. Almost all the parts of this plant exhibited various effects such as cardiovascular, gastrointestinal, hematological, and hepatorenal disorders inhibitory activities (Mahajan and Mehta 2007, Devaraj et al. 2007). Various publications have documented the antispasmodic, antitumor, antiulcer and hepatoprotective activities of M. oleifera (Ezeamuzie et al. 1996, Ali et al. 2004, Mahajan et al. 2007). It has also been reported to exhibit other diverse activities such as antiurolithiatic, antihypertensive, diuretic and cholesterol lowering activities (Anwar et al. 2007, Karadi et al. 2008).

The growing resistance of microorganisms to convectional antimicrobial agents is a source of concern to clinical microbiologists all over the world. As a result, efforts are being made to develop antimicrobial agents from local sources for better chemotherapeutic effects (Gills 1992). The demand for more natural antimicrobials has driven scientists to investigate the effectiveness of inhibitory compounds such as extracts from plants (Nasar-Abbas and Halkman 2004). Various publications have documented the antimicrobial activities of plant extracts (Mathabe et al. 2006, Ahmad and Aqil 2007). Thus plant extracts are promising natural antimicrobial agents with potential applications in pharmaceutical industry for controlling the pathogenic bacteria. Plant materials contain mostly glycoproteins that are toxic in nature; they play a key role in the control of various normal and pathological processes in living organisms. So far more than hundred lectins have been purified and characterized but their antibacterial and toxicological studies against mortality of brine shrimp is scanty. So our attention was to carry out the antibacterial and toxicological studies on the lectins purified from drumstick (M. oleifera) leaves.

\section{Materials and Methods}

Materials: The mature leaves of Moringa oleifera L. were collected from Kazla, Rajshahi. Pure strains of Escherichia coli (gram-negative), Shigella dysenteria (gram-negative) and Staphylococcus aureus (grampositive) were collected from the department of Pharmacy, University of Rajshahi, Bangladesh.

Isolation and purification of leaves: All the experimental procedure was carried out at $4-10^{\circ} \mathrm{C}$. Drumstick leaves (155 g) were grinded in a mortar and pestle. A very small amount of polyvinylpyrolidine (PVP) was added (to avoid the phenolic compounds and other coloring substances) and mixed uniformly with pre-cooled distilled water containing $0.2 \mathrm{M} \mathrm{NaCl}, \mathrm{pH}-6.5\left(6 \mathrm{ml} / \mathrm{g}\right.$ of leaf) and kept overnight at $4^{\circ} \mathrm{C}$ with occasional gentle shaking. The suspension was centrifuged $(8,000 \mathrm{~g})$ at $4^{\circ} \mathrm{C}$ for $15 \mathrm{~min}$. The clear supernatant was collected and adjusted to $100 \%$ saturation by adding solid ammonium sulfate. The resulting precipitate was collected by centrifugation, dissolved in minimum volume of pre-cooled distilled water and dialyzed against distilled water for $24 \mathrm{~h}$ with three changes and against $10 \mathrm{mM}$ Tris- $\mathrm{HCl}$ buffer, $\mathrm{pH}-8.4$ for $12 \mathrm{~h}$ at $4^{\circ} \mathrm{C}$. After centrifugation the clear supernatant was used as crude protein extract. 
Three lectins SLL-1, SLL-2 and SLL-3 were extracted and purified from small sized leaves by Gel filtration of $100 \%$ ammonium sulfate saturated crude protein extract on Sephadex G-75 followed by ion-exchange chromatography on DEAE and affinity chromatography on Sepharose-4B. The purities of the three lectins were checked by polyacrylamide slab gel electrophoresis (Khatun et al. 2007).

Antibacterial screening: The purified lectins were screened for their antibacterial activities by the standard Disc-Diffusion Method (Barry 1980, Bauer et al. 1966) by measuring the diameter of the inhibitory zones in $\mathrm{mm}$ using $30 \mu \mathrm{g} / 15 \mu \mathrm{l}$ of each of lectins in Tris-HCl buffer. The diameters of the zones of inhibitions of the samples were than compared with the diameter of the zone of inhibition produced by the standard antibiotic disc such as Doxycycline (DXT-30), erythromycin (E 15), ampicillin (Ap 10) and tetracycline (T 30). Blank discs were used as negative controls, which ensured that the residual solvents and the filter paper were not active themselves. Nutrients agar medium was used for determining antibacterial activity.

Lethality bioassay: Cytotoxicity study was done using Brine shrimp eggs placed in one side of a small tank divided by a net containing seawater ( $3.8 \% \mathrm{NaCl}$ solution) for hatching. In the other side of the tank, a light source was placed in order to attract nauplii. All the eggs hatched within two days and in this period the nauplii were also sufficiently matured for lethality bioassay experiment (Persoone1980, Mayer et al.1982, Mclaughlin 1990).

From the stock solutions, specific volumes were transferred to the different vials containing 10 living shrimps and then seawater was added to make the volume up to $5 \mathrm{ml}$ in each vial. The final concentration of the sample in the vials became $2,4,8,16$ and $32 \mu \mathrm{g} / \mathrm{ml}$ respectively. The experiments were carried out for the same concentration to get more accurate result and control experiment was performed similarly taking 10 living shrimps in $5 \mathrm{ml}$ seawater. The same assay procedure was performed for the standard Ampicillin trihydrate. After $24 \mathrm{~h}$ incubation, the vials were observed and the number of survival in each vial was counted using a magnifying glass.

\section{Results and Discussion}

As shown in Table1, the three lectins obtained from showed antibacterial activity against most of the tested bacteria. The results were compared with those of doxycycline (DXT-30), erythromycin (E 15), ampicillin (Ap 10) and tetracycline (T 30) as standard antibiotic. Of the three lectins SLL-3 showed lowest antimicrobial activity whereas SLL-1 showed highest activity against the three bacteria. The lectins at $30 \mu \mathrm{g} / 15 \mu \mathrm{l}$ concentration was reported to posses antibacterial activity against various gram positive and gram negative bacteria in particular against Bacillus subtilis, Bacillus megaterium, Streptococcus $\beta$-haemolyticus, Streptococcus aureus, Sarcina lutea, Shigella sonnei, E. coli, Klebsiella species, Shigella shiga, Shigella boydii, Shigella flexneriae, Shigella dysenteriae, Salmonella typhi and Pseudomonas aeuginosa (Ali et al. 2003).

The results of toxicity of experimental samples and standard Ampicillin trihydrate on brine shrimp are given in Table 2. All the three lectins and standard Ampicillin trihydrate exhibited significant cytotoxic activity in brine shrimp lethality bioassay. The mortality of the nauplii was found to increase with the increase in concentration of the samples and a plot of log of concentration vs. percent of mortality gave almost linear correlation (Fig. 1). From the graph the $50 \%$ mortality (LC 50 ) values of SLL-1, SLL-2 and SLL-3 were found to be $15.8,17.78$, and $14.12 \mu \mathrm{g} / \mathrm{mL}$ respectively.

It is evident from the results of brine shrimp lethality testing that the $L C_{50}$ value of SLL-3 was the lowest $(14.12 \mu \mathrm{g} / \mathrm{ml})$ indicating its higher toxicity. On the other hand these $\mathrm{LC}_{50}$ values of SLL-1 and SLL-2 were 
higher compared to SLL-3. The potency of the lectins was of the following order SLL-3 > SLL-1>SLL-2. This finding is very similar with that of mulberry seed (Morus spp) lectin (Hossain et al. 2002) and Cassia fistula L seed lectins (Ali et. al. 2003).

Table 1. Zone of inhibition exhibited by the lectins SLL-1, SLL-2 and SLL-3 purified from Drumstick (Moringa oleifera $\mathrm{L}$.) leaves and standard antibiotics against different bacterial strains

\begin{tabular}{lccc}
\hline \multirow{2}{*}{ Test Sample } & \multicolumn{3}{c}{ Diameter of zone of inhibition $(\mathrm{mm})$ against } \\
\cline { 2 - 4 } & E. coli & Sh. dysenteriae & St. aureus \\
\hline SLL-1 & 13 & 17 & 31 \\
SLL-2 & 11 & 14 & 24 \\
SLL-3 & 10 & 13 & 20 \\
Doxycycline (D-30) & 33 & 28 & 32 \\
Tetracycline (T 30) & - & 17 & 16 \\
Ampicillin (Ap 10) & - & 20 & 14 \\
Erythromycin (E 15) & - & 29 & 32 \\
\hline
\end{tabular}

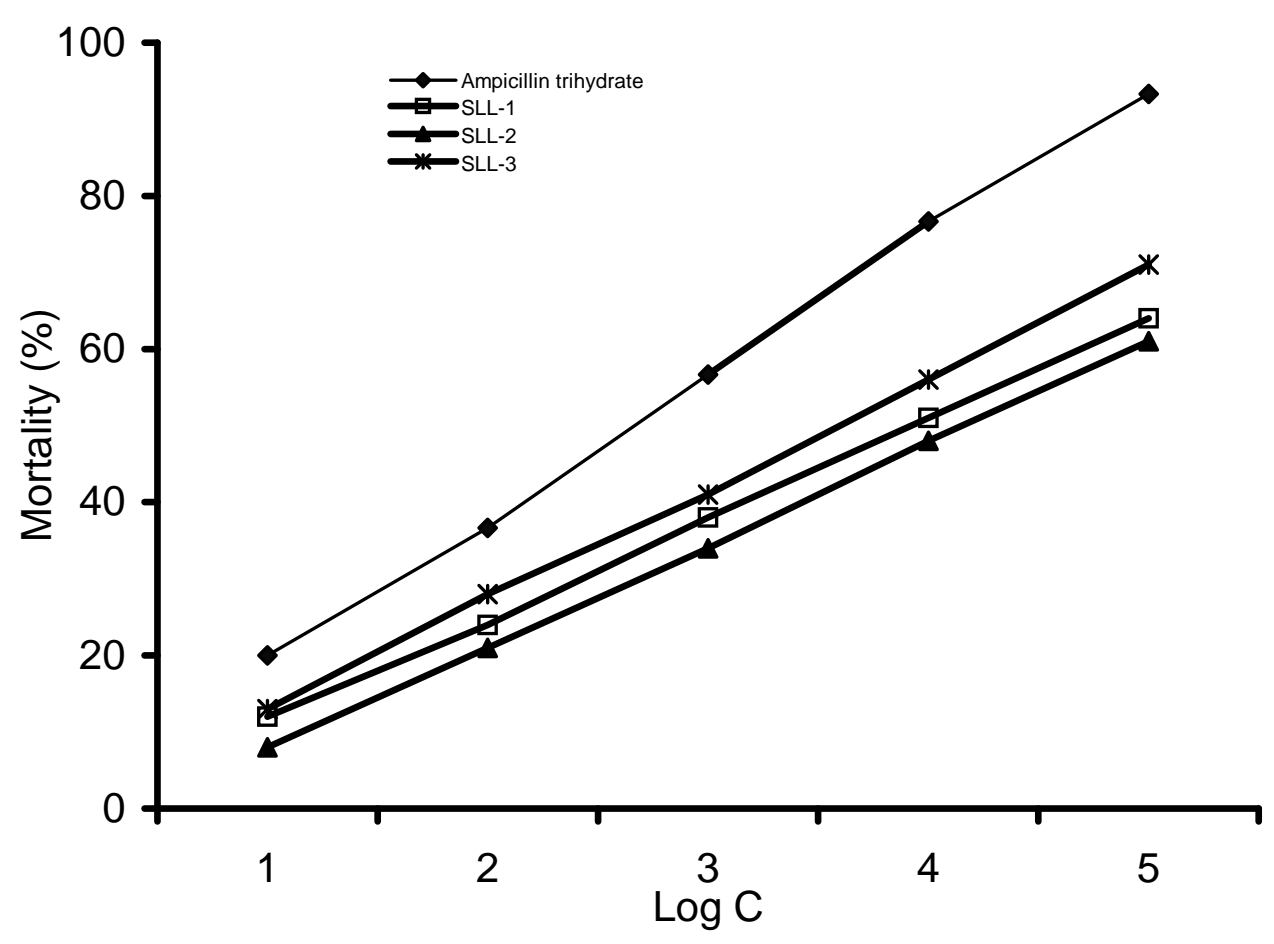

Fig. 1. Determination of $L C_{50}$ of Drumstick leaves lectins. 
Table 2. Effect of Drumstick leaves lectins and Ampicillin trihydrate on brine shrimp lethality bioassay

\begin{tabular}{ccccc}
\hline Test sample & $\begin{array}{c}\text { Conc. } \\
(\mu \mathrm{g} / \mathrm{ml})\end{array}$ & Log conc. (LogC) & $\begin{array}{c}\text { Mortality } \\
(\%)\end{array}$ & $\begin{array}{c}\text { LC50 } \\
(\mu \mathrm{g} / \mathrm{ml})\end{array}$ \\
\hline Control & 0 & 0 & 0 & \\
& 2 & 0.3010 & 20 & \\
Ampicillin trihydrate & 4 & 0.6020 & 36.66 & \\
& 8 & 0.9030 & 56.66 & \\
& 16 & 1.2041 & 76.66 & 15.8 \\
& 32 & 1.5051 & 93.33 & \\
SLL-1 & 2 & 0.3010 & 12 & \\
& 4 & 0.6020 & 24 & \\
& 8 & 0.9030 & 38 & \\
& 16 & 1.2041 & 51 & \\
& 32 & 1.5051 & 64 & \\
SLL-2 & 2 & 0.3010 & 8 & \\
& 4 & 0.6020 & 21 & \\
& 8 & 0.9030 & 34 & \\
& 16 & 1.2041 & 48 & \\
& 32 & 1.5051 & 61 & \\
& 2 & 0.3010 & 13 & \\
& 4 & 0.6020 & 28 & \\
& 8 & 0.9030 & 41 & \\
& 16 & 1.2041 & 56 & \\
& 32 & 1.5051 & 71 & \\
\hline
\end{tabular}

\section{References}

Ahmad I, Aqil F. 2007. Invitro efficacy of bioactive extracts of 15 medicinal plants against ESßL-producing multidrugresistant enteric bacteria. Microbiol Res 162, 264-275. doi:10.1016/j.micres.2006.06.010

Ali GH, El-Taweel GE, Ali MA. 2004. The cytotoxicity and antimicrobial efficiency of Moringa oleifera seeds extracts. Int J Environ Stud 61, 699-708. doi:10.1080/0020723042000189877

Ali MA, Sayeed MA, Absar N. 2003. Antibacterial Activity and Cytotoxicity of Three Lectins Purified from Cassia fistula Linn. Seeds. J Med Sci 3(3), 240-244. doi:10.3923/jms.2003.240.244

Anwar F, Latif S, Ashraf M, Gilani AH. 2007. Moringa oleifera: A food plant with multiple medicinal uses. Phytother Res 21, 17-25. doi:10.1002/ptr.2023

Barry AL. 1980. Procedures for testing antimicrobial agents in agar media. In: Antibiotic in laboratory medicine. (Lorian V ed.). William and Wilkins Co. Baltimore, USA, 1-23 p.

Bauer AW, Kirby WWM, Sherris JC, Turck M. 1966. Antibiotic susceptibility testing by a standardized single disc method. Am J Clin 45, 493-496.

Boyd WC. 1970. Lectins. Ann NY Acad Sci 169, 168-190. doi:10.1111/j.1749-6632.1970.tb55984.x

Devaraj VC, Asad M, Prasad S. 2007. Effect of leaves and fruits of Moringa oleifera on gastric and duodenal ulcers. Pharmaceutical Biol 45, 332-338. doi:10.1080/13880200701212924 
Ezeamuzie IC, Ambakederemo AW, Shode FO, Ekwebelem SC. 1996. Antiinflammatory effects of Moringa oleifera root extract. Pharmaceutical Biol 34, 207-212. doi:10.1076/phbi.34.3.207.13211

Fuglie LJ. 1999. The miracle tree Moringa oleifera. Natural nutrition for the tropics. Church World Service. Dakar, Senegal, pp. 63.

Gills LS. 1992. Ethno medical uses of plants in Nigeria. Ilupeju Press Ltd, pp. 165-250.

Hossain MA, Chowdhury JA, Chowdhury AA, Ahmed KU, Absar N . 2002. Brine Shrimp Bioassay of the Lectins isolated from Mulberry Seeds (Morus spp), Bangladesh Pharm J 12 (3), 5-7.

Karadi RV, Palkar MB, Gaviraj EN, Gadge NB, Mannur VS, Alagawadi KR. 2008. Antiurolithiatic property of Moringa oleifera root bark. Pharmaceutical Biol, 46, 861-865. doi:10.1080/13880200802367189

Khatun S, Ashraduzzaman MN, Absar N, Pervin F, Ali MA, Bari L, Karim MR, Hassan P. 2007. Purification and Characterization of Three Galactose Specific Lectins from Drumstick (Moringa oleifera Lam.) Leaves. J Chin Chem Soc 54(2), 1-8.

Lin JY, Lee TC, Hu ST, Tung TC. 1981. Isolation of four cytotoxic proteins and one agglutinin from Jequiriti bean (Abrus precatorius). Toxicon 19, 41-51. doi:10.1016/0041-0101(81)90116-1

Linear IE, Sharon N, Goldstein IJ. 1986. The Lectins: Properties, Functions and Applications in Biology and Medicine. Academic Press, New York, 600 pp.

Lis $\mathrm{H}$, Sharon N. 1986. Lectins as Molecules and as tools. Ann Rev Biochem 55, 36-67. doi:10.1146/annurev.bi.55.070186.000343

Mahajan SG, Mali RG, Mehta AA. 2007. Effect of Moringa oleifera Lam. Seed extract on toluene diisocyanate-induced immune-mediated inflammatory responses in rats. J Immunotoxicol 4, 85-96. doi:10.1080/15476910701337472

Mahajan SG, Mehta AA. 2007. Inhibitory action of ethanolic extract of seeds of Moringa oleifera Lam. on systemic and local anaphylaxis. J Immunotoxicol 4, 287-294. doi:10.1080/15476910701680137

Mathabe MC, Nikolova RV, Lall N, Nyazema NZ. 2006. Antibacterial activities of medicinal plants used for the treatment of diarrhoea in Limpopo Province, South Africa. J Ethnopharmacol 105, 286-293. doi:10.1016/j.jep.2006.01.029

Mayer BN, Ferringi NR, Putnam JE, Jacobsen LB, Nichols DE, Mclaughlin JL. 1982. Brine Shrimp: A convenient bioassay for active constituent. Planta Medica 45, 31-34. doi:10.1055/s-2007-971236

Mclaughlin JL.1990. Bench tops bioassay for the discovery of bioactive compounds in higher plants. Brenena, $29 \mathrm{pp}$.

Nadkarni KM. 1976. The Indian Materia Medica. Popular Prokashany, Bombay, 810pp.

Nasar-Abbas SM, Halkman AK. 2004. Antimicrobial effect of water extract of sumac (Rhus coriaria L.) on the growth of some food borne bacteria including pathogens. Int J Food Microbiol, 97, 63-69. doi:10.1016/j.ijfoodmicro.2004.04.009

Persoone G. 1980. Proceeding of the international symposium on brine shrimp Artemia salina. Volumes 1-3, University Press. Witteren, Belgium.

Sastri B N. 1962. The Wealth of India. Council of Scientific and Industrial Research, New Delhi, 425-429.

Sharon N, Lis H. 1989. Lectins. Chapman and Hall, London. 127pp.

Sulaiman MR, Zakaria ZA, Bujarimin AS, Somchit MN, Israf DA, Moin S. 2008. Evaluation of Moringa oleifera aqueous extract for antinociceptive and anti-inflammatory activities in animal models. Pharmaceutical Biol 46, 838-845. doi:10.1080/13880200802366710 